\title{
Seasonal changes in leaf chlorophyll a content and morphology in a sub-tropical mangrove forest of the Mexican Pacific
}

\author{
Francisco Flores-de-Santiago ${ }^{1, *}{ }^{,}$,ohn M. Kovacs $^{2}{ }^{2}$ Francisco Flores-Verdugo ${ }^{3}$ \\ ${ }^{1}$ Department of Geography, The University of Western Ontario, London, Ontario N6A 5C2, Canada \\ ${ }^{2}$ Department of Geography, Nipissing University, North Bay, Ontario P1B 8L7, Canada \\ ${ }^{3}$ Instituto de Ciencias del Mar y Limnología, Universidad Nacional Autónoma de México, Mazatlán, Sinaloa 82000, Mexico
}

\begin{abstract}
Changes in chlorophyll a ( $\mathrm{chl} a$ ), leaf area, and leaf length need to be considered when developing ecological assessments of mangrove forests where distinct seasons occur. The purpose of this study was to assess such changes between the dry and rainy seasons in a variety of mangrove classes. Six different classes were examined, consisting of 3 species (white mangrove Laguncularia racemosa, red mangrove Rhizophora mangle, and black mangrove Avicennia germinans) that were either healthy or in poor condition. In total, 360 leaf samples were taken from the upper and lower canopy for chl a content. Additionally, leaf area index (LAI) was recorded at the same locations. For all the poor-condition classes, we observed an increase in the chl a content during the rainy season in both the upper and lower canopies. Moreover, dwarf black mangrove was the only poor-condition class which did not show an increase in leaf length during the rainy season. The healthy white mangrove showed no seasonal difference in chl $a$ in the upper canopy, but the lower canopy did have higher chl a content during the dry season as well as a lower LAI. The healthy red mangrove also did not show any seasonal difference in chl a content, but the upper canopy had a higher chl a content. For the healthy black mangrove, no seasonal differences were found in chl a content, LAI, or leaf morphology in both upper and lower canopies. Consequently, for future endeavors we recommend that seasonal changes in the upper canopy be considered, especially when examining stands in poor condition.
\end{abstract}

KEY WORDS: Mangrove $\cdot$ Seasonal changes $\cdot$ Chlorophyll $a \cdot$ Leaf area index $\cdot$ LAI

\section{INTRODUCTION}

Leaf chemical properties are the principal determinants of plant physiology and of highly active biochemical processes such as photosynthesis (Evain et al. 2004). Among the most common variations that interact with plant photosynthesis are diurnal changes of incident irradiance, ambient temperature, and humidity (Schulze \& Caldwell 1994). Additionally, seasonal changes in the availability of water and nutrients (Gilman et al. 2008) affect the effectiveness of pigments in light capture and utilization (Evain et al. 2004). Amongst the various leaf pigments, chlorophyll $a(\mathrm{chl} a$ ) is a key compound responsible for photosynthesis, physiology, and other biological functions in plants. Consequently, changes in chl a can indicate plant growth (Raven et al. 1992) or disturbances from stressors (Blackburn 2007).

The aforementioned disturbances are commonplace in high, locally stressed canopies such as mangrove forests. These forested wetlands are predominantly intertidal and occur worldwide in the sub-tropics and tropics (Nagelkerken et al. 2008) along sheltered and shallow water coastlines (Ho- 
garth 1999) where high irradiation is the norm (Evain et al. 2004) and natural and anthropogenic disturbances are common. The importance of ecological field surveys of these systems may have implications in developing fast and accurate assessments regarding the state of these highly productive forested habitats for future conservation measures. Mangroves are an essential resource for a variety of local activities (Walters et al. 2008), provide for a variety of macrofaunal interactions (Cannicci et al. 2008), are highly productive (Komiyama et al. 2008), and provide habitat for a variety of terrestrial and marine fauna (Nagelkerken et al. 2008).

For mangroves, the concentrations of leaf pigments can be associated with environmental factors such as ambient temperature/sunlight (Saenger 2002), water availability (Lacerda 2002), and salinity (Steinke et al. 1993). Thus, in a sub-tropical mangrove forest where fresh water availability is seasonal, precipitation patterns could affect the physiological development of the mangrove trees, resulting in an increase or decrease of ground salinity (Field 1995). As a consequence, in sub-tropical regions there could be a seasonal decrease in net primary productivity (Saenger 2002) and growth (Raven et al. 1992). As well, a seasonal increase in the availability of sulfate in water may occur, which could increase anaerobic decomposition (Saintilan \& Wilton 2001, Rogers et al. 2005) and thus potentially alter the competition between mangrove species (Lacerda 2002) resulting in decreasing diversity within mangrove areas (Duke et al. 1998). In anthropogenically stressed mangroves, these conditions (e.g. hypersalinity) may be exasperated, resulting in large-scale mangrove loss or degradation as shown in a mangrove forest just south of our study area (Kovacs et al. 2005).

Each species of mangrove has a particular range of tolerance to environmental factors such as water salinity. For example, some species are relatively intolerant to hypersaline conditions (e.g. Rhizophora mangle), whereas others are quite capable of tolerating very high salinities of over 60 (e.g. Avicennia germinans; Moroyoqui-Rojo \& Flores-Verdugo 2005). These differences among the species could be assessed using leaf biophysical variables such as leaf area index (LAI), leaf area, leaf length, and chl a concentration. Specifically, seasonal differences in LAI and chl a concentration could be related to organic carbon dynamics such as litterfall decomposition rates (Flores-Verdugo et al. 1987, Kristensen et al. 2008), nutrient cycling characteristics (Feller et al. 1999), and mangrove paleoecological reconstructions (Ellison 2008). The variability of inter-species leaf morphology (e.g. leaf area, leaf length) could be associated with faunal retention rates (Cannicci et al. 2008), mangrove ecosystem seasonal dynamics (Berger et al. 2008), and differences in canopy ecological habitat for faunal species (Nagelkerken et al. 2008). Moreover, all of these data could be valuable in describing and predicting seasonal patterns of forest productivity (Raven et al. 1992).

Yet another potentially important characteristic to consider is seasonal change in the vertical distribution of pigments within the mangrove canopy. Such potential variability could depend on many factors, including acclimation to light penetration (Saenger 2002), characteristics of each species (Raven et al. 1992), and the environment itself (Ciganda et al. 2009). Moreover, it could provide key information regarding our understanding of the role that mangrove species play in response to a variety of factors, including climate change. The main objective of this investigation was to compare the leaf biophysical parameters (chl a content, leaf area, and leaf length) between the rainy and dry seasons in a degraded mangrove forest of the Mexican Pacific. This would also include assessing whether any seasonal differences can occur in the upper and lower canopies. These data can be of utmost importance when trying to establish effective monitoring programs of mangrove forest productivity. In particular, these data can be used to determine the optimal times to map estimated mangrove biomass from remotely sensed data. This is extremely important given that the spectral vegetation indices used in such operations are directly dependent on the leaf canopy structure and leaf chl a concentration.

\section{MATERIALS AND METHODS}

\section{Study area}

Data were collected along the south end of the Urias mangrove system (Fig. 1) during 2 seasons, the dry season of May 2010 (mean precipitation of $0.1 \mathrm{~mm}$ ) and at the end of the rainy season in October 2010 (mean precipitation of $190 \mathrm{~mm}$; INEGI 2010). According to the federal government (INEGI 2010), the historical metrological data (1986 to 2010) indicates that the 2010 dry and rainy seasons were normal in regards to precipitation and ambient temperature. The driest and rainiest years were 1994 and 2000, respectively.

The Urias system is a shallow, saline, vertically mixed body of water of approximately $18 \mathrm{~km}^{2}$ 
which is located in the coastal plain of the southeastern Gulf of California $\left(23^{\circ} 10^{\prime} \mathrm{N}, 106^{\circ} 20^{\prime} \mathrm{W}\right)$. Previous authors have indicated that during the dry season, this estuary becomes fully inversed (Alvarez 1977, Agraz-Hernández 1999, MoroyoquiRojo \& Flores-Verdugo 2005). In other words, the salinity increases monotonically from the mouth to the head. It has also been suggested that the removal of water by the mangrove trees (Hogarth 1999) and the high estuarine evaporation rates (Ridd \& Stieglitz 2002) may combine to raise the soil salinity during the dry season, resulting in areas characterized by a hypersaline state which are common in this system. The fringe mangroves, which consist of healthy trees, receive ample water from the adjacent river at high tide during the rainy season. The basin mangrove communities, consisting primarily of dwarf trees and/or trees in poor condition, receive runoff water from the mainland, decreasing soil salinity during this season. Healthy mangrove trees located along the

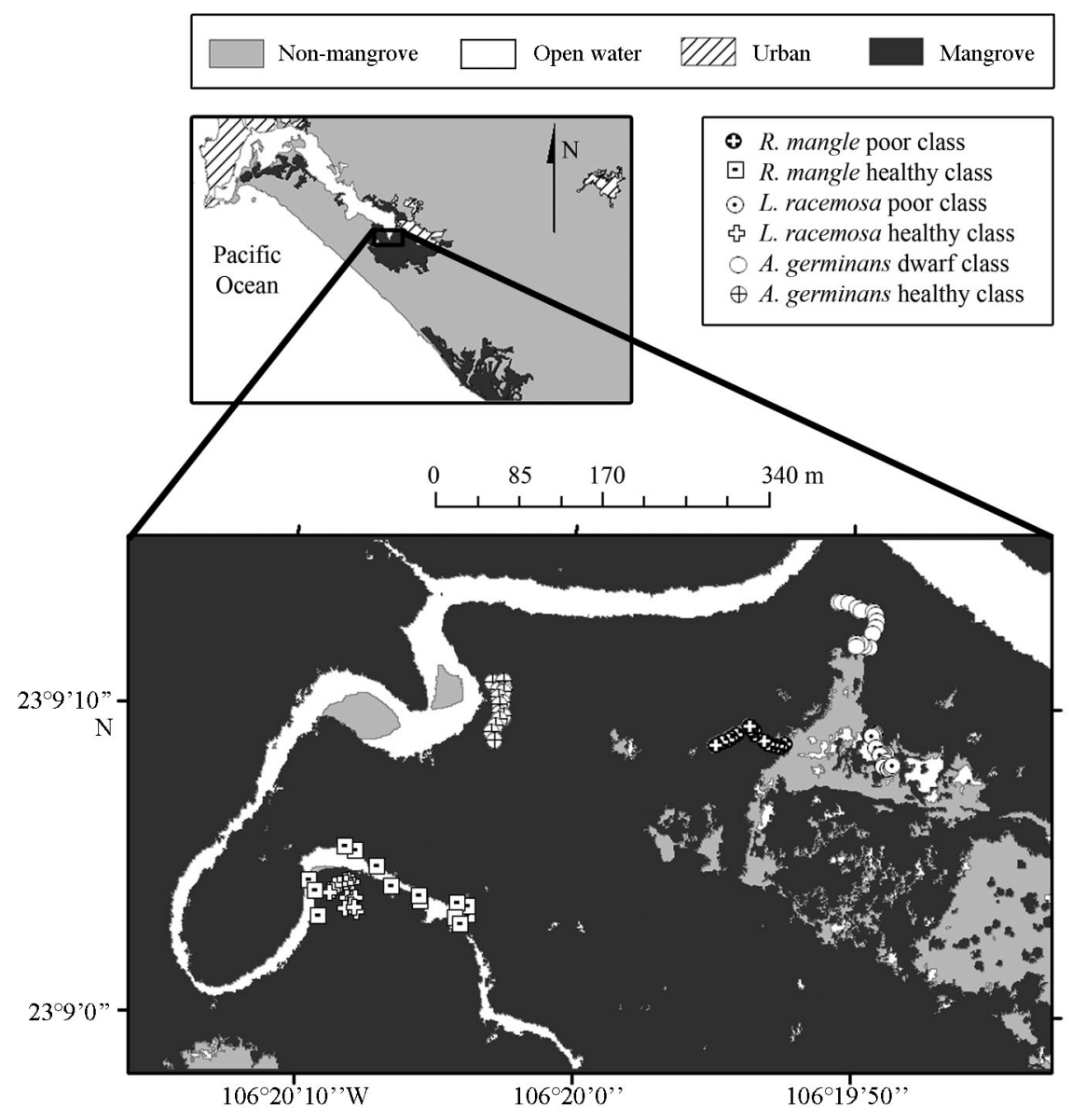

Fig. 1. Data collection sites at the south end of the Urias mangrove system fringe are exposed to frequent full strength tidal influence (up to $1.5 \mathrm{~m}$; Hogarth 1999), while the poor/dwarf mangrove trees are located more inland exposed to infrequent tidal inundation (Saenger 2002).

The surface of the substrate in the mangrove is generally smooth with a few small channels and depressions, with a relatively gentle overall slope extending towards the open water of the main tidal channel (Moroyoqui-Rojo \& Flores-Verdugo 2005). The lagoon is partly bordered by a mangrove forest ecosystem, which is best developed along the edge and supports 3 dominant species: red mangrove Rhizophora mangle, black mangrove Avicennia germinans, and white mangrove Laguncularia racemosa. Based on height and distance to water, the mangroves in this arid sub-tropical region differ considerably from their wet tropical counterparts in 2 major ways. Firstly, river discharge into the wetlands is highly seasonal, with very large flows in the wet season followed by several months of negligible discharge. Secondly, large areas of mangrove and saltpan often infringe on this coastal type lagoon. As a result, many of these arid coastal lagoons become hypersaline for much of the year.

Similar to the mangrove system just south of this region, anthropogenic changes, particularly related to hydrological modifications (e.g. roads, aquaculture diversion) have resulted in a degraded system with prominent areas now consisting of dwarf and poorcondition stands of each species (Kovacs et al. 2008, 2009). Consequently, 6 classes of mangrove have been identified for this system: dwarf and poorcondition red, black, and white mangrove and healthy red, black, and white mangrove. Although the descriptions of these classes are qualitative, their classification has been done quantitatively utilizing standard image-processing methods based on their unique spectral properties as identified from remotely sensed digital data (Kovacs et al. 2008, Zhang et al. in press). Moreover, a similar remotely sensed mangrove classification scheme based on identical spectral data was recently justified using statistical methods based on in situ biophysical parameter data for a forest just south of this region (Kovacs et al. 2011). 


\section{LAI collection}

LAI is defined as the 1-sided leaf area per ground surface area (Wilhelm et al. 2000) found in the nearinfrared spectrum of the canopy reflectance properties. With regards to the LAI measurements, an AccuPAR LP-80 (Decagon Devices) ceptometer was used to quantify in situ LAI for every species of mangrove in this system. The device measures the incoming photosynthetically active radiation (PAR) through 80 sensors incorporated along the linear probe. We quantified LAI based on 1 above- and $>1$ belowcanopy reading using the following equation:

$$
\mathrm{LAI}=\frac{\left[\left(1-\frac{1}{2 K}\right) f b-1\right] \ln \tau}{A(1-0.47 f b)}
$$

where $f b$ is beam fraction. $(A)$ is determined by the instrument based upon the leaf distribution and the canopy leaf absorption qualities. For this sampling routine it was assumed to be 0.9 . Tau $(\tau)$ is the ratio of PAR measured below the canopy to PAR above the canopy, and the extinction coefficient $(K)$ is determined automatically by the LP-80 using the latitude, longitude, and the minutes of the day to calculate the zenith angle $(\theta)$ :

$$
K=\frac{1}{2 \operatorname{Cos} \theta}
$$

The beam fraction ( $f b$ ) depends on the high and low limits of the potential PAR and the zenith angle with the following set of equations:

$$
\begin{gathered}
r=\frac{\mathrm{PAR}}{2550(\operatorname{Cos} \theta)} \\
f b 1=48.57+r[-59.024+r(24.835)] \\
f b=1.395+r[-14.47+r(f b 1)]
\end{gathered}
$$

A stratified random sampling method was employed to make sure each mangrove class within the system was analyzed. For each class, we sampled 15 sites in a longitudinal pattern taking approximately 8 LAI readings per site. A post-processing GPS was used to ensure that seasonal readings could be collected for each site.

\section{Leaf chl a concentration and leaf morphology}

As with the LAI sites, we selected 3 mangrove trees from each class for the pigment analysis. For each tree, 10 leaves were taken from the top of the canopy (i.e. upper canopy) and 10 leaves from the lower canopy using an extendable pole with a cutter. In order to select just the mature leaves, each of the samples was chosen between the third and fifth leaves from the tip. A sub-meter GPS location was recorded so that the same leaf collection site could be used for both seasons.

Once cut, each leaf was stored in a plastic bag within a small cooler at $4^{\circ} \mathrm{C}$ for transportation to the laboratory. The leaf area and length were analyzed using an LI-3000C Portable Area Meter device.

Due to the difference in leaf morphology between the mangrove species, we followed the method of F. Flores-de-Santiago et al. (unpubl.), in which we normalized chl a per unit area $\left(\mathrm{mg} \mathrm{m}^{-2}\right)$ using the dimensions of the diameter of a copper cylinder. Specifically, 1 leaf circle $(1.25 \mathrm{~cm}$ in diameter $)$ from each leaf of each sample was cut out with the cylinder. Care was taken to avoid the circles that included main leaf veins. Plant material for each sample was then dissolved with $100 \mathrm{ml}$ of $80 \%$ acetone. A spectrophotometric assay was then conducted to extract information of peak absorption at 646 and $663 \mathrm{~nm}$.

\section{Statistical analysis}

\section{Normality test}

We used a Q-Q plot to test the normality of error of estimates for all data (i.e. LAI, chl a, leaf area, leaf length). This test is based on an ordered plot of residual errors of an equation against normal quantiles $q_{(j)}$. In this test, if the data lie in proximity to a straight line, then we cannot reject the null hypothesis of normality. To measure the straightness of the Q-Q plot, we used the correlation coefficient of the $\mathrm{Q}-\mathrm{Q}$ plot, which is defined as follows:

$$
\mathrm{r}_{\mathrm{Q}}=\frac{\sum_{j=1}^{n}\left(x_{j}-\bar{x}\right)\left(q_{j}-\bar{q}\right)}{\sqrt{\sum_{j=1}^{n}\left(x_{j}-\bar{x}\right)^{2}} \sqrt{\sum_{j=1}^{n}\left(q_{j}-\bar{q}\right)^{2}}}
$$

where $(x)$ is the theoretical quantile, $(q)$ is the sample quantile, $(j)$ are the points of paired quantiles, and $(n)$ is the total observation number. Consequently, at the $5 \%$ significance level $(\alpha=0.05)$ and $n=60$, we used the critical value of 0.98 (Johnson \& Wichern 1992).

\section{Seasonal changes and LAI statistical testing}

Differences in chl a concentrations, leaf area, leaf length, and LAI were tested using Minitab ${ }^{\circledR}$ and Origin ${ }^{\circledR}$ software. When the data were not normally distributed, each of the 3 parameters was tested using non-parametrical statistics (Mann-Whitney $U$-test). 
However, averages and standard deviations are provided though not analyzed for comparison between the mangrove classes. The tests were used to examine for differences between the upper and lower canopies for both seasons.

\section{RESULTS}

\section{Seasonal assessment and LAI}

Of all comparisons for normality, most $\mathrm{r}_{\mathrm{Q}}$ values were below the critical value; therefore, we used non-parametric tests. Significant differences in chl a concentration $(\mathrm{p}<0.05, \mathrm{n}=30)$ were found between seasons for the upper and lower canopies of the white poor, red poor, and black dwarf classes (Table 1). Among these differences, it is clear that all 3 species experienced an increase in leaf chl a concentration during the rainy season (Fig. 2). By contrast, for healthy mangroves of all 3 species, no significant differences in chl a concentration were observed between seasons $(\mathrm{p}<0.05, \mathrm{n}=30)$ in the upper leaves (Table 1). With the exception of the 'white healthy' class, which had higher chl a concentration during the dry season (Fig. 2), a lack of seasonal differences was also observed for the lower canopy leaves of the healthy mangroves.

With regards to the leaf area and leaf length, no data were recorded for the white poor upper leaves during October due to data loss (corrupt file). Most of the classes showed no significant seasonal differences $(p<0.05, n=30)$ in leaf area. In the case of
Table 2. Laguncularia racemosa, Rhizophora mangle, and Avicennia germinans. Mann-Whitney $U$-test for the leaf area index (LAI) between seasons $(\mathrm{n}=15)$. ${ }^{*}$ Significant $U$ value at $\mathrm{p} \leq 0.05$ (2-tailed)

\begin{tabular}{|lccc|}
\hline \multirow{2}{*}{ Class } & \multicolumn{2}{c|}{ Median LAI } & $U$ \\
\cline { 2 - 3 } & May & October & \\
\hline L. racemosa & & 1.2 & 106 \\
Poor & 1.4 & 3.6 & $28^{*}$ \\
Healthy & 2.5 & & \\
R. mangle & & 2.4 & 68 \\
Poor & 2.1 & 5.1 & 151 \\
Healthy & 5.7 & 1.5 & \\
A. germinans & & 2.9 & 137 \\
Dwarf & 1.5 & & \\
Healthy & 3.6 & & \\
\hline
\end{tabular}

white and black healthy upper leaves (Table 1), a significant increase in leaf area was recorded during the rainy season (Fig. 3). Moreover, the length of the leaves in the upper canopy increased significantly $(\mathrm{p}<0.05, \mathrm{n}=30)$ for white healthy, red poor, and red healthy mangroves during the rainy season (Table 1 , Fig. 4). No significant differences $(\mathrm{p}<0.05, \mathrm{n}=30$ ) were found in the lower canopies of black healthy, black dwarf, and red healthy (Table 1).

With regards to LAI, no significant difference $(\mathrm{p}<$ $0.05, \mathrm{n}=15$ ) was observed between the seasons for the white poor, red poor, red healthy, black dwarf, and black healthy mangrove classes (Table 2). However, a significant difference $(\mathrm{p}<0.05, \mathrm{n}=15)$ was found in the white healthy mangrove with an increase in LAI occurring during the rainy season (Fig. 5).
Table 1. Laguncularia racemosa, Rhizophora mangle, and Avicennia germinans. Mann-Whitney $U$-test median values for chlorophyll a (chl a), leaf area, and leaf length between seasons $(\mathrm{n}=30)$. LR: L. racemosa; RM: R. mangle; AG: A. germinans. ${ }^{*}$ Significant $U$ values at $\mathrm{p} \leq 0.05$ (2-tailed)

\begin{tabular}{|c|c|c|c|c|c|c|c|c|c|}
\hline \multirow{2}{*}{$\begin{array}{l}\text { Species } \\
\text { and class }\end{array}$} & \multicolumn{3}{|c|}{$\mathrm{Chl} a\left(\mathrm{mg} \mathrm{m}^{-2}\right)$} & \multicolumn{3}{|c|}{ Leaf area $\left(\mathrm{cm}^{2}\right)$} & \multicolumn{3}{|c|}{ Leaf length $(\mathrm{cm})$} \\
\hline & May & Oct & $U$ & May & Oct & $U$ & May & Oct & $U$ \\
\hline \multicolumn{10}{|l|}{ Upper } \\
\hline LR poor & 20.9 & 26.6 & $15^{*}$ & \multicolumn{3}{|c|}{ No data } & \multicolumn{3}{|c|}{ No data } \\
\hline LR healthy & 31.6 & 30.9 & 536 & 14.7 & 18.2 & $301^{*}$ & 6 & 10 & $48^{*}$ \\
\hline RM poor & 24.9 & 33.3 & $117^{*}$ & 34.7 & 29.0 & 541 & 9.6 & 12.3 & 94 \\
\hline RM healthy & 43.2 & 42.6 & 418 & 48.1 & 50.6 & 420 & 11.3 & 14.6 & $90^{*}$ \\
\hline AG dwarf & 24.7 & 36.2 & $15^{*}$ & 10.9 & 10.4 & 503 & 99.5 & 9.7 & 430 \\
\hline AG healthy & 32.0 & 36.7 & 341 & 20.2 & 24.0 & $306^{*}$ & 13.0 & 13 & 479 \\
\hline \multicolumn{10}{|l|}{ Lower } \\
\hline LR poor & 23.5 & 26.5 & $160^{*}$ & 19.1 & 19.2 & 424 & 6.7 & 9.2 & $65^{*}$ \\
\hline LR healthy & 33.4 & 27.0 & $809^{*}$ & 14.3 & 15.5 & 371 & 6.2 & 9.6 & $41^{*}$ \\
\hline RM poor & 31.3 & 39.9 & $194^{*}$ & 27.9 & 25.8 & 406 & 8.4 & 12.5 & $42^{*}$ \\
\hline RM healthy & 36.7 & 37.8 & 376 & 49.1 & 46.9 & 529 & 15.5 & 15.4 & 500 \\
\hline AG dwarf & 32.1 & 36.7 & $225^{*}$ & 13.1 & 10.2 & $583^{*}$ & 8.8 & 9.1 & 454 \\
\hline AG healthy & 32.2 & 33.2 & 354 & 29.6 & 29.0 & 514 & 13.5 & 12.3 & 543 \\
\hline
\end{tabular}

\section{Upper versus lower canopy}

Dry season

During the dry season, chl a concentration shows no significant difference $(\mathrm{p}<0.05, \mathrm{n}=30$ ) between upper and lower canopy leaves for the white healthy and the black healthy mangroves (Table 3). The white poor, red poor, and black dwarf classes showed a higher chl a concentration within the lower leaves when compared to the red healthy, which presented higher chl a content in the upper leaves (Table 3). With regards to leaf area, the white healthy, red healthy, and black dwarf mangroves did not show any significant differences $(p<0.05$, 

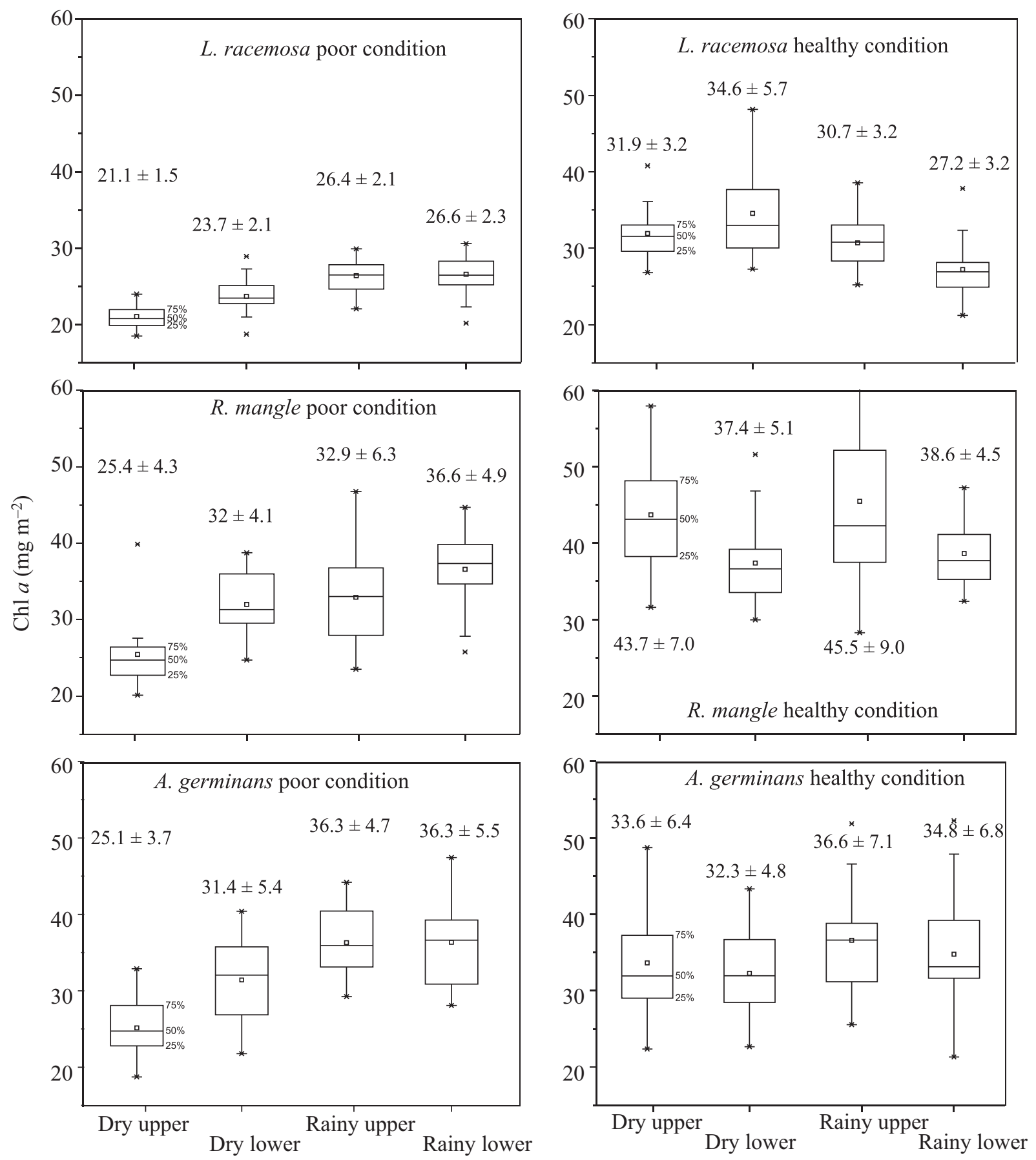

Fig. 2. Laguncularia racemosa, Rhizophora mangle and Avicennia germinans. Upper and lower canopy leaf chlorophyll a (chl a) concentration by season. Dry and rainy seasons are represented by the months of May and October, respectively. Each box plot depicts the mean (small square), the minimum sample, the lower quartile (25\%), the median (50\%), the upper quartile $(75 \%)$, the maximum sample, and the lowest and highest sample within the 1.5 interquartile ranges of the lower and upper quartile $(\times)$. Also, mean $\pm \mathrm{SD}$ is shown at the top of each box plot

$\mathrm{n}=30$ ). The red poor mangroves did have significantly higher leaf area in the upper leaves. In contrast, the white poor and black healthy showed an increase in leaf area in the lower leaves. The length of leaves showed no significant difference $(\mathrm{p}<0.05, \mathrm{n}=30)$ in the white healthy, black dwarf, and black healthy classes. The white poor and the red healthy did have significantly higher leaf lengths in the lower leaves, whereas the red poor had significantly higher leaf lengths in the upper canopy. 

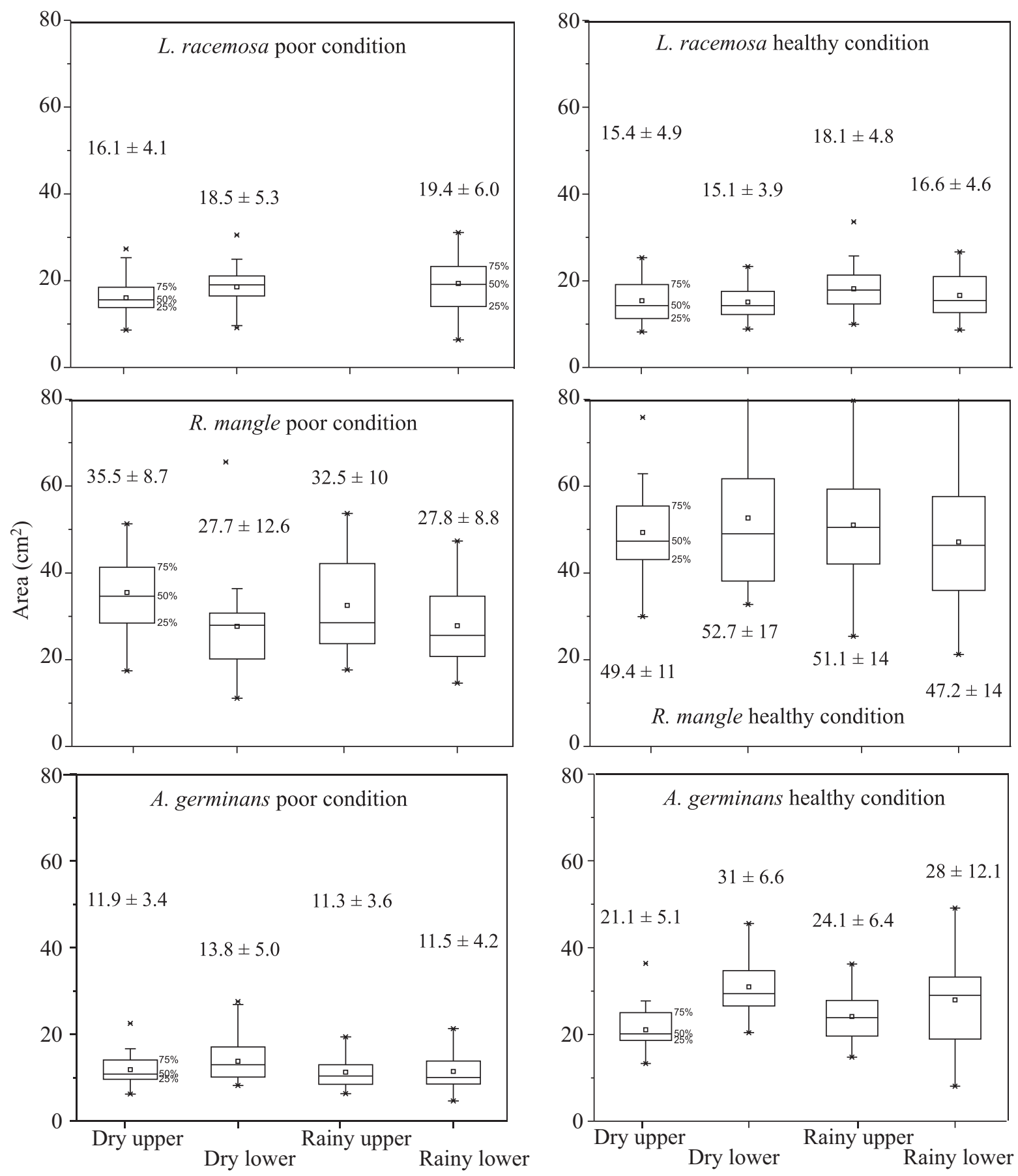

Fig. 3. Laguncularia racemosa, Rhizophora mangle and Avicennia germinans. Upper and lower canopy leaf chlorophyll a (chl a) concentration by season. Dry and rainy seasons are represented by the months of May and October, respectively. Each box plot depicts the mean (small square), the minimum sample, the lower quartile (25\%), the median (50\%), the upper quartile $(75 \%)$, the maximum sample, and the lowest and highest sample within the 1.5 interquartile ranges of the lower and upper quartile $(x)$. Also, mean $\pm \mathrm{SD}$ is shown at the top of each box plot

\section{Rainy season}

With regards to the rainy season (Table 3), the chl a concentration showed no significant difference $(\mathrm{p}<0.05, \mathrm{n}=30$ ) between the lower and upper leaves in the white poor, black dwarf, and black healthy mangroves. The white healthy and the red healthy classes presented higher chl a concentration in the upper leaves, and the red poor showed higher content in the lower leaves. 

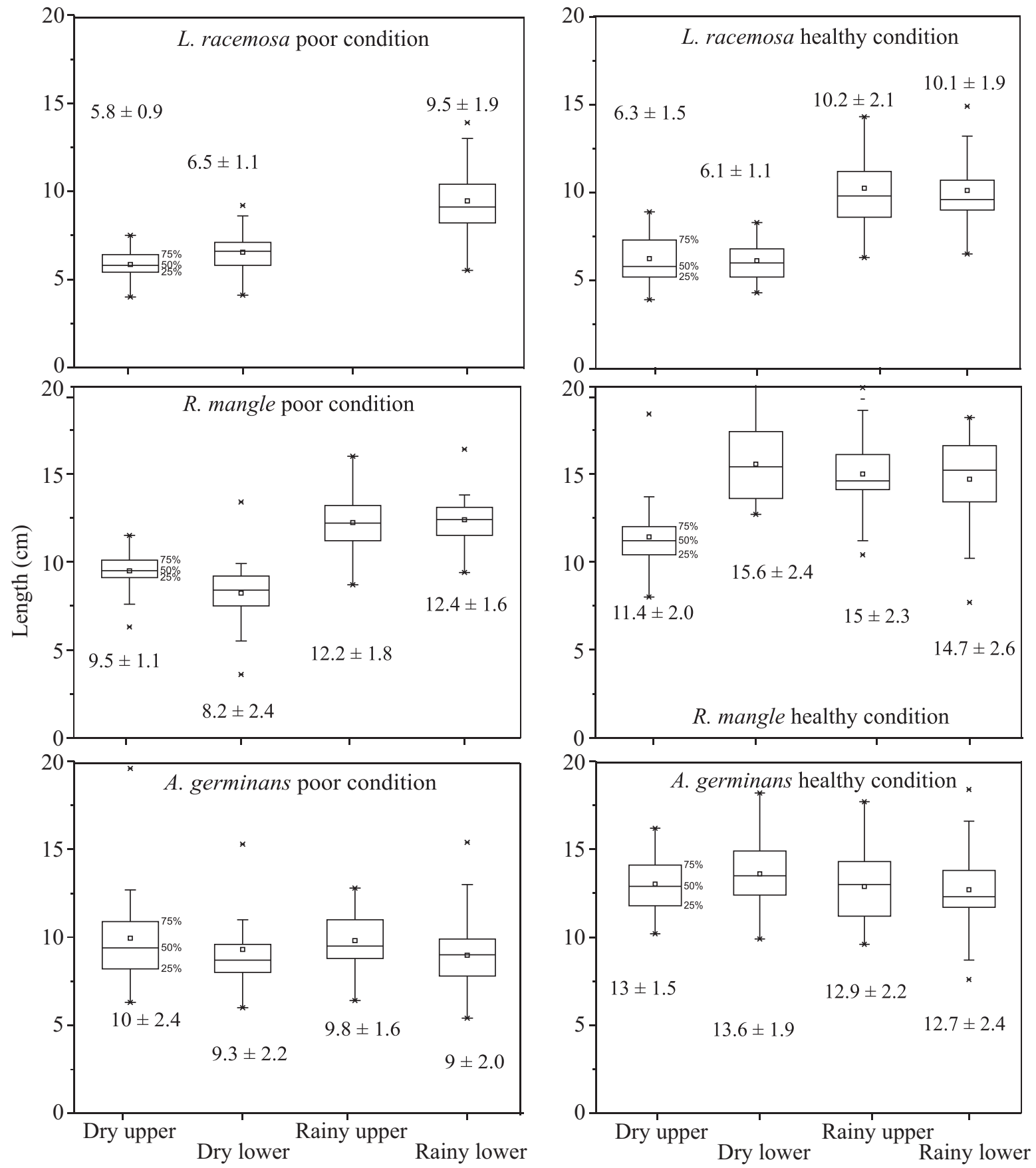

Fig. 4. Laguncularia racemosa, Rhizophora mangle and Avicennia germinans. Upper and lower canopy leaf chlorophyll a (chl a) concentration by season. Dry and rainy seasons are represented by the months of May and October, respectively. Each box plot depicts the mean (small square), the minimum sample, the lower quartile (25\%), the median (50\%), the upper quartile $(75 \%)$, the maximum sample, and the lowest and highest sample within the 1.5 interquartile ranges of the lower and upper quartile $(x)$. Also, mean $\pm \mathrm{SD}$ is shown at the top of each box plot

No significant differences in leaf area were found among all 6 classes. Regarding leaf length, no significant differences were found with the exception of the black dwarf, which had significantly larger leaves in the upper canopy during this season.

\section{DISCUSSION AND CONCLUSIONS}

\section{Mangrove community}

Where seasonal gradients are involved, the pattern of chl a concentration and leaf morphology can be 

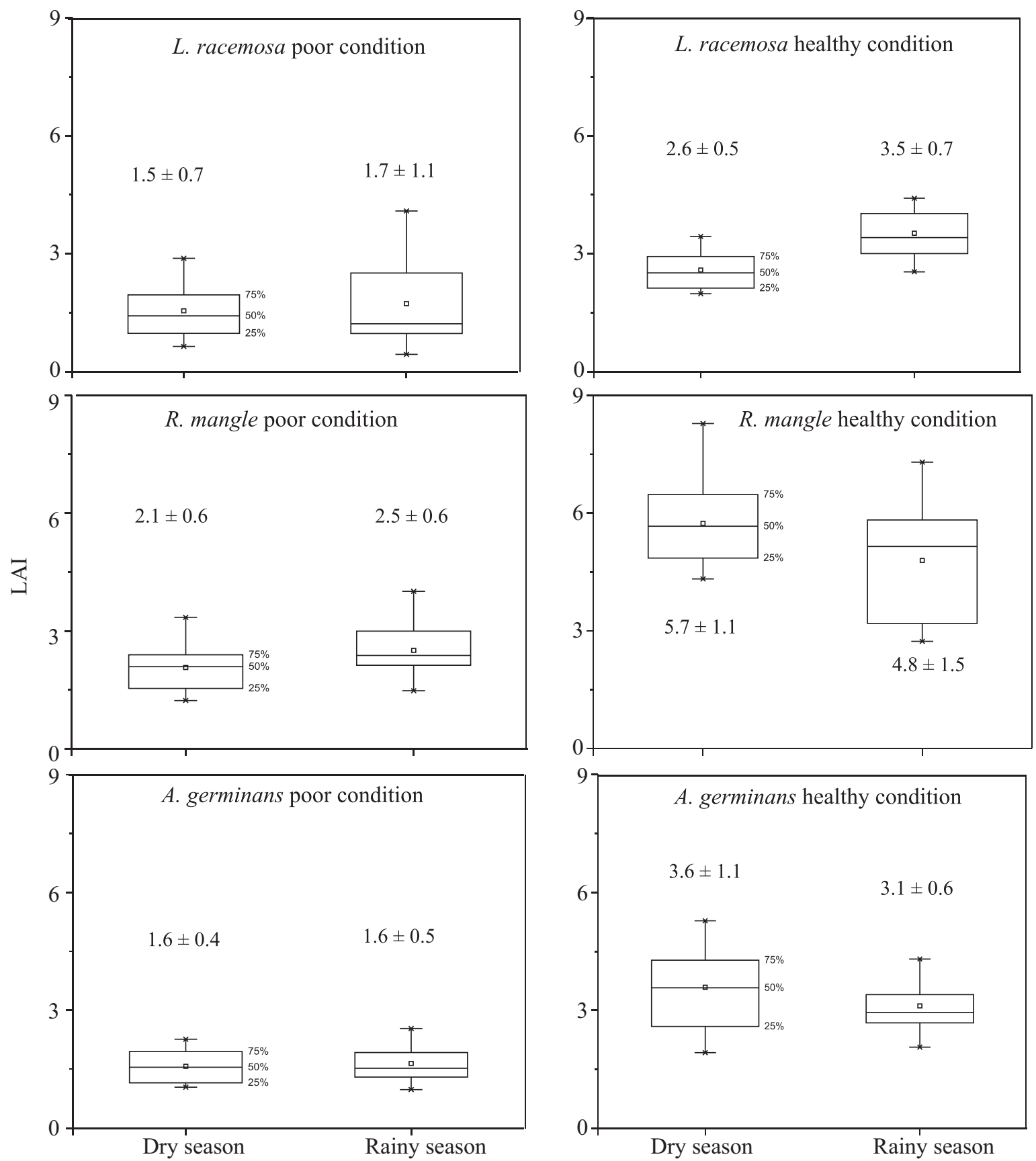

Fig. 5. Laguncularia racemosa, Rhizophora mangle and Avicennia germinans. Upper and lower canopy leaf chlorophyll a ( $\mathrm{chl}$ a) concentration by season. Dry and rainy seasons are represented by the months of May and October, respectively. Each box plot depicts the mean (small square), the minimum sample, the lower quartile (25\%), the median (50\%), the upper quartile $(75 \%)$, the maximum sample, and the lowest and highest sample within the 1.5 interquartile ranges of the lower and upper quartile $(\times)$. Also, mean $\pm \mathrm{SD}$ is shown at the top of each box plot

used to express the ecological changes of species as key indicators of the physiological stage, productivity, and stress of a mangrove forest. In this investigation, we determined that variability in chl a can occur amongst various mangrove classes found within a degraded forest of the sub-tropics. Specifically, in this study area, the chl a concen- tration of all 3 mangrove species in poor condition showed seasonal dependence, unlike those that were healthy. As previously described by Kovacs et al. (2011), the fringe mangrove of this region of Mexico is typically healthy, whereas basin mangrove is more often found in a poor/dwarf condition. 
The leaf morphology patterns observed in this study agree with Tomlinson (1986), in that we found bigger leaves in the healthy classes, in particular red and black mangrove, while black dwarf and white poor showed the lowest leaf area and length (Figs. 3 $\& 4)$. This is suggestive of a direct relationship between the leaf morphology and the physical state of the trees.

\section{White mangrove}

It has been noted that different light and shade requirements in adults of Laguncularia racemosa are indicative of a shade-intolerant response (Smith 1992, McKee 1995), suggesting a pattern in which leaves from the lower canopy and under thicker cover receive less light during the rainy season. As seen with the increase in LAI during the rainy season in healthy stands, this could decrease chl a concentration in the lower leaves and therefore result in more stress because of the low irradiances as depicted in Fig. 2. By contrast, the apparent lack of change in the chl a concentration in healthy leaves from the upper canopy suggests that the aforementioned shade-intolerant pattern from the lower canopy is present in this type of healthy forest. However, the higher leaf area and leaf length during the rainy season may indicate that at the top of the canopy, the chl a concentration has no apparent dependence on the morphology of the leaves.

Table 3. Laguncularia racemosa, Rhizophora mangle, and Avicennia germinans. Mann-Whitney $U$-test median values for chlorophyll a (chl a), leaf area, and leaf length between the upper and lower canopy in both seasons $(n=30)$, viz. rainy (October) and dry (May). LR: L. racemosa, RM: R. mangle, AG: A. germinans. ${ }^{*}$ Significant $U$ values at $\mathrm{p} \leq 0.05$ (2-tailed)

\begin{tabular}{|c|c|c|c|c|c|c|c|c|c|}
\hline \multirow{2}{*}{$\begin{array}{l}\text { Species } \\
\text { and class }\end{array}$} & \multicolumn{3}{|c|}{ Chl a $\left(\mathrm{mg} \mathrm{m}^{-2}\right)$} & \multicolumn{3}{|c|}{ Leaf area $\left(\mathrm{cm}^{2}\right)$} & \multicolumn{3}{|c|}{ Leaf length $(\mathrm{cm})$} \\
\hline & Upper & Lower & $U$ & Upper & Lower & $U$ & Upper & Lower & r $U$ \\
\hline \multicolumn{10}{|l|}{ May } \\
\hline LR poor & 20.9 & 23.5 & $142^{*}$ & 15.6 & 19.1 & $291^{*}$ & 5.9 & 6.7 & $269^{*}$ \\
\hline LR healthy & 31.6 & 33.4 & 338 & 14.7 & 14.3 & 449 & 6 & 6.2 & 463 \\
\hline RM poor & 24.9 & 31.3 & $110^{*}$ & 34.7 & 27.9 & $658^{*}$ & 9.6 & 8.4 & $661^{*}$ \\
\hline RM healthy & 43.2 & 36.7 & $697^{*}$ & 48.1 & 49.1 & 425 & 11.3 & 15.5 & $68^{*}$ \\
\hline AG dwarf & 24.7 & 32.1 & $154^{*}$ & 10.9 & 13.1 & 357 & 9.5 & 8.8 & 551 \\
\hline AG healthy & 32.0 & 32.2 & 485 & 20.2 & 29.6 & $91^{*}$ & 13.0 & 13.5 & 368 \\
\hline \multicolumn{10}{|l|}{ October } \\
\hline LR poor & 26.6 & 26.5 & 419 & \multicolumn{3}{|c|}{ No data } & \multicolumn{3}{|c|}{ No data } \\
\hline LR healthy & 30.9 & 27.0 & $723^{*}$ & 18.2 & 15.5 & 536 & 10 & 9.6 & 482 \\
\hline RM poor & 33.3 & 37.5 & $266^{*}$ & 29.0 & 25.8 & 581 & 12.3 & 12.5 & 440 \\
\hline RM healthy & 52.2 & 41.6 & $676^{*}$ & 50.6 & 46.9 & 523 & 14.6 & 15.4 & 451 \\
\hline AG dwarf & 36.2 & 36.7 & 453 & 10.4 & 10.2 & 454 & 9.7 & 9.1 & $594^{*}$ \\
\hline AG healthy & 36.7 & 33.2 & 518 & 24.0 & 29.0 & 346 & 13 & 12.3 & 455 \\
\hline
\end{tabular}

Regarding the white mangrove in poor condition, the shade-intolerant pattern (Smith 1992, McKee 1995) was not observed, as there was no change in LAI. Moreover, the higher chl a concentration and leaf length during the rainy season indicate that this poor-condition forest is distinctly seasonal in its development. Tomlinson (1986) indicated that for this species, branching occurs during the rainy season, with an extended period of inactivity during the dry season, suggesting that at high irradiances and lack of fresh water, the vegetative survival and competitiveness of Laguncularia racemosa could depend on an efficient display of foliage and the ability to respond to environmental changes and stress.

\section{Red mangrove}

Regarding the poor condition, the increases in chl a concentration and leaf length during the rainy season in both upper and lower canopies suggest that this type of forest greatly depends on fresh water availability and shade as previously reported by Farnsworth \& Ellison (1996). In contrast, the lack of seasonal change within the healthy forest in LAI and leaf morphology suggests a moderate sun-shade flexibility. Ellison \& Farnsworth (1993) reported that Rhizophora mangle is capable of adapting to different light levels, including gaps within the canopy. It was noted in the field that the majority of healthy $R$. mangle were found in a continuous stand along the main channel where no other species of mangrove could constrain the availability of light. The lack of observed seasonal change in LAI, chl $a$, and leaf area in this study would suggest an adaptation of fringe $R$. mangle to constant tidal flushing.

In this study, a high chl a concentration was found in the upper leaves of healthy red mangrove during the rainy season. Lugo et al. (1975) indicated that the non-shaded leaves (i.e. upper canopy) of this species may show a net photosynthetic rate twice as high as that of the shaded leaves (lower canopy). Regardless of canopy composition, it has been reported that Rhizophora mangle trees can assume a shade-tolerant (Farnsworth \& Ellison 1996) and shade-intolerant (Snedaker 1995) pattern. In this study, the red mangrove in poor condition could 
be indicative of a shade-tolerant pattern, with higher concentrations of chl a in the lower canopy. By contrast, the healthy red mangrove in this study would indicate a more shade-intolerant trend, with higher chl a concentration in the upper canopy where the availability of light is higher as compared to the shaded leaves in the lower canopy.

\section{Black mangrove}

The patterns of the black dwarf mangrove suggest a distinctive seasonal pattern similar to the red mangrove in poor condition, with the only difference being no significant seasonal change in LAI. The low chl a concentration during the dry season could be the result of increasing soil temperature and decreasing humidity (Sherman et al. 2000), as these trees are typically close or adjacent to drier uplands (i.e. saltpan). Ball \& Critchley (1982) reported that shaded leaves of Avicennia germinans can have a higher chl $a$ content during the dry season, suggesting a more intolerant pattern to light availability (Feller et al. 2007), and thus revealing a high vulnerability to photoinhibition (Cheeseman 1994).

Within healthy black mangrove forest, Gratani (1997) suggested that the major adaptation of leaves in a lower canopy with low irradiance is the development of thinner leaves. In our study, we did not measure leaf thickness. However, the apparent lack of change in leaf morphology may suggest that healthy Avicennia germinans is well adapted to shaded conditions as mentioned by Attiwill \& Clough (1980). In the present study, the lack of change in LAI and chl $a$ for the shaded leaves may suggest that this forest does not present significant seasonal changes.

Monitoring the seasonal development of mangrove species and conditions along a mixed environment is important for future research, particularly when dealing with studies that examine remotely sensed data, carbon allocation, or biomass. The observed differences between seasons for some of the species and conditions examined would indicate a clear pattern that this study site is dependent primarily on fresh water availability. Given the large geographic extent and inaccessibility of this type of sub-tropical canopy, remote-sensing image acquisitions are commonly used to monitor and map mangroves. In particular, for degraded systems, remotely sensed imagery is often used to monitor parameters directly related to the LAI and/or chlorophyll content. For example, many estimates of biomass or LAI from remote sensing platforms are dependent on standard vegetation indices (e.g. the normalized difference vegetation index) which are calculated from spectral reflectance directly related to the canopy thickness and leaf chl a content (Jensen 2005).

Consequently, knowing the seasonal changes in these parameters would allow remote sensing specialists to identify the optimal time to acquire imagery for accurate biomass or LAI mapping and monitoring. Moreover, collecting these data on an annual basis could be beneficial for monitoring potential impacts on these particular ecosystems resulting from abnormal years of precipitation and/or temperature.

Acknowledgements. F.F.S. and J.M.K. acknowledge, respectively, financial support for this research through grants provided by the Consejo Nacional de Ciencia y Tecnología of México (grant \#198885) and the Natural Sciences and Engineering Research Council of Canada (grant \#249496-06). Funding for the field campaigns was provided by F.F.V. through The Instituto de Ciencias del Mar y Limnología, estación Mazatlán, México.

\section{LITERATURE CITED}

Agraz-Hernández CM (1999) Reforestación experimental de manglares en ecosistemas lagunares estuarinos de la costa noroccidental de México. PhD dissertation, Universidad Autónoma de Nuevo León, Monterrey

Alvarez LR (1977) Estudio hidrobiológico de los esteros del Astillero Urias y la Sirena, adyacentes a Mazatlán, Sinaloa, México. MSc dissertation, Universidad Nacional Autónoma de México, Mazatlán

Attiwill PM, Clough BF (1980) Carbon dioxide and water vapor exchange in the white mangrove. Photosynthetica 14:40-47

Ball MC, Critchley C (1982) Photosynthetic response to irradiance by the grey mangrove, Avicennia marina, grown under different light regimes. Plant Physiol 70:1101-1106

Berger U, Rivera-Monroy VH, Doyle TW, Dahdouh-Guebas F and others (2008) Advances and limitations of individual-based models to analyze and predict dynamics of mangrove forest: a review. Aquat Bot 89:260-274

Blackburn GA (2007) Hyperspectral remote sensing of plant pigments. J Exp Bot 58:855-867

> Cannicci S, Burrows D, Fratini S, Smith TJ III, Offenberg J, Dahdouh-Guebas F (2008) Faunal impact on vegetation structure and ecosystem function in mangrove forests: a review. Aquat Bot 89:186-200

Cheeseman JM (1994) Depressions of photosynthesis in mangrove canopies. In: Baker NR, Bowyer JR (eds) Photoinhibition of photosynthesis - from molecular mechanisms to the field. Bios Scientific Publishers, Oxford, p 379-391

Ciganda V, Gitelson A, Schepers J (2009) Non-destructive determination of maize leaf and canopy chlorophyll content. J Plant Physiol 166:157-167

Duke NC, Ball MC, Ellison JC (1998) Factors influencing biodiversity and distributional gradients in mangroves. Glob Ecol Biogeogr 7:27-47

Ellison JC (2008) Long-term retrospection on mangrove 
development using sediment cores and pollen analysis: a review. Aquat Bot 89:93-104

Ellison AM, Farnsworth EJ (1993) Seedling survivorship, growth and response to disturbance in Belizean mangal. Am J Bot 80:1137-1145

Evain S, Flexas J, Moya I (2004) A new instrument for passive remote sensing: 2. Measurement of leaf and canopy reflectance changes at $531 \mathrm{~nm}$ and their relationship with photosynthesis and chlorophyll fluorescence. Remote Sens Environ 91:175-185

Farnsworth EJ, Ellison AM (1996) Sun-shade adaptability of the red mangrove, Rhizophora mangle (Rhizophoraceae): changes through ontogeny at several levels of biological organization. Am J Bot 83:1131-1143

Feller IC, Whigham DF, O'Neill JP, McKee KL (1999) Effects of nutrient enrichment on within-stand cycling in a mangrove forest. Ecology 80:2193-2205

Feller IC, Lovelock CE, McKee KL (2007) Nutrient addition differentially affects ecological processes of Avicennia germinans in nitrogen versus phosphorus limited mangrove ecosystems. Ecosyst 10:347-359

- Field C (1995) Impact of expected climate change on mangroves. Hydrobiologia 295:75-81

Flores-Verdugo F, Day JW, Briseño-Dueñas R (1987) Structure, litter fall, decomposition, and detritus dynamics of mangroves in a Mexican coastal lagoon with an ephemeral inlet. Mar Ecol Prog Ser 35:83-90

- Gilman EL, Ellison J, Duke NC, Field C (2008) Threats to mangrove from climate change and adaptation options: a review. Aquat Bot 89:237-250

Gratani L (1997) Canopy structure, vertical radiation profile and photosynthetic function in a Quercus ilex evergreen forest. Photosynthetica 33:139-149

Hogarth PJ (1999) The biology of mangroves. Oxford University Press, New York, NY

INEGI (Instituto Nacional de Estadística y Geografía) (2010) Anuario estadistico del estado de Sinaloa. INEGI, Mexico City

Jensen JR (2005) Introductory digital image processing: a remote sensing perspective. Pearson Education, London

Johnson RA, Wichern DW (1992) Applied multivariate statistical analysis. Prentice-Hall, Englewood Cliffs, NJ

Komiyama A, Eong OJ, Poungparn S (2008) Allometry, biomass, and productivity of mangrove forest: a review. Aquat Bot 89:128-137

Kovacs JM, Wang J, Flores-Verdugo F (2005) Mapping mangrove leaf area index at the species level using IKONOS and LAI-2000 sensors for the Agua Brava Lagoon, Mexican Pacific. Estuar Coast Shelf Sci 62:377-384

Kovacs JM, Zhang C, Flores-Verdugo F (2008) Mapping the condition of mangroves of the Mexican Pacific using Cband ENVISAT ASAR and Landsat optical data. Cienc Mar 34:407-418

Kovacs JM, King JML, Flores-de-Santiago F, Flores-Verdugo F (2009) Evaluating the condition of a mangrove forest of the Mexican Pacific based on an estimated leaf area index mapping approach. Environ Monit Assess 157:137-149

Kovacs JM, Liu Y, Zhang C, Flores-Verdugo F, Flores de Santiago F (2011) A field based statistical approach for validating a remotely sensed mangrove forest classification scheme. Wetl Ecol Manag 19:409-421

Kristensen E, Bouillonn S, Dittmar T, Marchand C (2008)

Editorial responsibility: Hans Heinrich Janssen,

Oldendorf/Luhe, Germany
Organic carbon dynamics in mangrove ecosystems: a review. Aquat Bot 89:201-219

Lacerda LD (2002) Mangrove ecosystems: function and management. Springer, Berlin

Lugo AE, Evink G, Brinson MM, Broce A, Snedaker SC (1975) Diurnal rates of photosynthesis, respiration and transpiration in mangrove forests in south Florida. In: Golley FB, Medina E (eds) Tropical ecological systems: trends in terrestrial and aquatic research. Springer, Berlin, p 335-350

McKee KL (1995) Interspecific variation in growth, biomass partitioning, and defensive characteristics of neotropical mangrove seedlings: response to light and nutrient availability. Am J Bot 82:299-307

Moroyoqui-Rojo L, Flores-Verdugo FJ (2005). Análisis de la eficiencia en la remoción de nutrientes en un sistema experimental silvo pesquero (manglar-ictiopfauna) con recirculación de agua. MSc dissertation, CIDIR Instituto Politécnico Nacional de México, Guasave

> Nagelkerken I, Blaber SJM, Bouillon S, Green P and others (2008) The habitat function of mangrove for terrestrial and marine fauna: a review. Aquat Bot 89:155-185

Raven PH, Evert RF, Eichhorn SE (1992) Biology of plants. W. H. Freemann \& Company Press, New York, NY

Ridd PV, Stieglitz T (2002) Dry season salinity changes in arid estuaries fringed by mangroves and saltflats. Estuar Coast Shelf Sci 54:1039-1049

Rogers K, Saintilan N, Heijnis H (2005) Mangrove encroachment of salt marsh in Western Port Bay, Victoria: the role of sedimentation, subsidence, and sea level rise. Estuaries 28:551-559

Saenger P (2002) Mangrove ecology, silviculture and conservation. Kluwer Academic Publishers, Dordrecht

Saintilan N, Wilton K (2001) Change in the distribution of mangroves and saltmarshes in Jervis Bay, Australia. Wetl Ecol Manag 9:409-420

Schulze ED, Caldwell MM (eds) (1994) Ecophysiology of photosynthesis. Springer-Verlag, Berlin

Sherman RE, Fahey TJ, Battles JJ (2000) Small-scale disturbance and regeneration dynamics in a neotropical mangrove forest. J Ecol 88:165-178

Smith TJ (1992) Forest structure. In: Robertson AI, Alongi DM (eds) Tropical mangrove ecosystems. Coastal and Estuarine Studies No. 41. American Geophysical Union, Washington, DC, p 101-136

Snedaker SC (1995) Mangroves and climate change in the Florida and Caribbean region: scenarios and hypotheses. Hydrobiologia 295:43-49

Steinke TD, Holland AJ, Singh Y (1993) Leaching losses during decomposition of mangrove leaf litter. S Afr J Bot 59: 21-25

Tomlinson PB (1986) The botany of mangroves. Cambridge University Press, Cambridge

Walters BB, Rönnbäck P, Kovacs JM, Crona B and others (2008) Ethnobiology, socio-economics and management of mangrove forests: a review. Aquat Bot 89:220-236

Wilhelm WW, Ruwe K, Schlemmer MR (2000) Comparison of three leaf area index meters in a corn canopy. Crop Sci 40:1179-1183

Zhang C, Liu Y, Kovacs JM, Flores-Verdugo F, Flores-deSantiago F, Chen K (in press) The hyperspectral response to varying levels of leaf pigments collected from a degraded mangrove forest. J Appl Remote Sens

Submitted: May 17, 2011; Accepted: November 1, 2011

Proofs received from author(s): December 16, 2011 